Thus our results are generally similar to other evaluations of the child development programme.

We know of only one other programme with broadly similar goals-namely, the "head start" programme in the United States.910 However, it is aimed at preschool children and based on a professional model of intervention, so that comparisons would be inappropriate.

These results tend to confirm that the empowerment approach to promoting parenting skills developed by Barker $^{1}$ is sound, practical, and effective. That the programme can be delivered effectively by non-professionals, themselves mothers living in disadvantaged areas, is of great interest. We would, however, like to compare the cost effectiveness of this approach with that of intervention by professional workers.

At the end of 1991 the overall budget for the community mothers' programme was around £Ir 50000 . This included the salaries of 11 family development nurses, a clerical assistant, and $£$ Ir 2 per visit paid to a community mother as well as other non-remunerative items. One hundred and thirty community mothers served throughout 1991, visiting between 900 and 1000 first time parents. Indeed, such has been the success of the programme that other Irish health authorities have expressed an interest in developing similar projects, and discussions are under way.

Possibly community mothers or other non-professional workers might serve in other areas of health promotion also. This and the present issues merit further study.

We thank Eastern Health Board personnel for their help, particularly M Kelly, T Parle, T Keggan, A Savage, C Byrne, and P O'Doherty; Walter Barker, originator of the child development programme; the Department of Social Work, University of Bristol; and the parents and children who form the basis of this report. We are greatly indebted to Barry Merriman for the statistical analysis. This project was supported by the Bernard van Leer Foundation, The Hague.

1 Barker W. The child development programme: a collaborative programme linking parents, community and health visitors. Bristol: Early Childhood Development Unit, University of Bristol, 1984

2 Barker $\mathrm{W}$, Anderson $\mathrm{R}$. The child development programme: an evaluation of process and outcome. Bristol: Early Childhood Development Unit, University of Bristol, 1984.

3 Health Education Bureau. Recommended dietary allowances. Dublin: Department of Health, 1983.

4 Percy P, Barker W. The child development programme. Midwife, Health Visitor and Community Nurse 1986;22:235-40.

5 Barker W. Parent power. Nursing Standard 1990;4:43-4.

6 World Health Organisation. Targets for health for all. Copenhagen: WHO Regional Office for Europe, 1985.

7 Barker W. Child development programme-evaluation document 8. Bristol: Early Childhood Development Unit, University of Bristol, 1987.

8 Barker W, Anderson R, Chalmers C. Early health and development monitorevaluation document 11. Belfast: preliminary findings on the results of the child development programme. Bristol: Childhood Development Unit, University of Bristol, and Eastern Health and Social Services Board, Belfast, 1987.

9 Besharov DJ, Hartle TW. Head start: making a popular programme work. Pediatrics 1987;79:440-1.

10 Kotelchuck M, Richmond JB. Head start: evolution of a successful comprehensive development programme. Pediatrics 1987;79:441-4.

(Accepted 25 March 1993)

\title{
What are the complications of influenza and can they be prevented? Experience from the 1989 epidemic of $\mathrm{H} 3 \mathrm{~N} 2$ influenza $A$ in general practice
}

\author{
Ann Marie Connolly, R L Salmon, B Lervy, D H Williams
}

PHLS Communicable

Disease Surveillance Centre (Welsh Unit), Cardiff CF4 3QX

Ann Marie Connolly, senior registrar in public health medicine

R L Salmon, consultant epidemiologist

Llys Meddyg, The Surgery, Morriston, Swansea

SA6 6HU

B Lervy, general practitioner

Eglwysbach Surgery, Pontypridd, Mid

Glamorgan CF37 2AA

D H Williams, general

practitioner

Correspondence to:

Dr R L Salmon

BMf 1993;306: 1452-4

\section{Abstract}

Objectives-In an epidemic: to measure the incidence and risk of complications of influenza; to determine the effect of pre-existing disease on complications; to estimate vaccine uptake and efficacy.

Design-Case-control study.

Setting-Primary care: two group practices.

Subjects-342 of the 395 cases of clinically diagnosed influenza reported to the general practice surveillance of infectious diseases scheme of the Public Health Laboratory Service during the 1989 epidemic, and 342 age and sex matched controls.

Interventions-Examination of records.

Main outcome measures-Documented recognised complications; hospital admission; previous vaccination.

Results-Of 15 recognised complications, bronchitis was the commonest (rate 190.1/1000 cases) and significantly commoner in cases (summary odds ratio 9.7 ) after adjusting for higher consultation rates (mean 6.1 per annum $v 4.2$ among controls; $p<0.0001)$. No deaths were recorded. The risk of bronchitis complicating influenza was higher in patients with pre-existing illnesses regarded as an indication for vaccination (odds ratio 3.3; $p<0.0001$ ). Observed vaccination efficacy in those with pre-existing illnesses and in elderly subjects was high (63\% and $77 \%$ respectively) but uptake was low (4.5\% and $6 \cdot 1 \%$ respectively).

Conclusions-Bronchitis complicates about one fifth of all cases of influenza presenting to general practitioners. Patients with pre-existing illnesses regarded as an indication for vaccination are particu- larly at risk. Vaccine uptake is extremely low, precluding an unequivocal demonstration of a protective effect.

\section{Introduction}

Influenza is the most important viral infection of the respiratory tract, ${ }^{12}$ partly because of the scale of epidemics and partly because of complications, which include excess mortality, ${ }^{3}$ several medical conditions, ${ }^{4}$ ${ }^{8}$ and exacerbations of pre-existing diseases. ${ }^{9}$ However, little is known about the expected incidence of these complications. Knowledge tends to be based on complications observed in hospital. Of 237 English language reports since 1966 on influenza and complications cited in Medline, none measure the incidence of complications in the community.

In 1989 there was the first epidemic of influenza $A$ in the United Kingdom since $1975 .{ }^{10}$ We studied the epidemic in Wales in order $(a)$ to measure the incidence and risk of complications, $(b)$ to identify the rate of hospitalisation, (c) to determine the effect of preexisting disease on the development of complications, and $(d)$ to estimate vaccine uptake and efficacy.

\section{Subjects and methods}

Influenza in Wales is monitored as part of the general practice surveillance of infectious diseases scheme of the Public Health Laboratory Service Communicable Disease Surveillance Centre (Welsh Unit). " This scheme comprises 34 spotter practices that provide weekly returns of cases of eight infectious diseases seen 


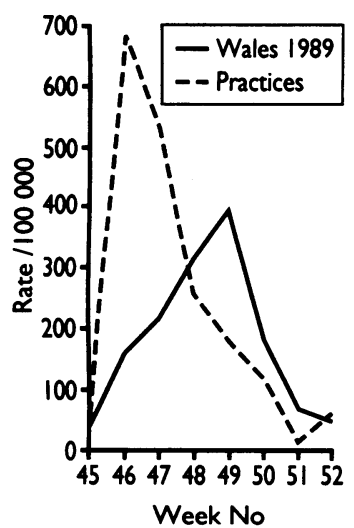

Rates of influenza recorded in two general practices during 1989 by them. Influenza is defined clinically as upper respiratory tract symptoms, fever, chills, myalgia, and cough. Two practices with a list size of 22076 patients which had kept complete registers identifying the cases of influenza reported to the scheme during the eight weeks of the epidemic took part.

Cases were patients reported as having influenza between weeks 45 and 52 of 1989 . Controls, one per case, matched for sex and age (within one year for ages $0-4,2$ years for ages 5-14, and five years for ages 15 plus) were chosen as the next patient, at least three places from the case, on the practice age-sex register fulfilling the matching criteria. Those who had influenza within three months before or after the date of onset in the case or who had registered with the practice after the epidemic were excluded. An alternative control 10 places or more away from the case was chosen. Patients' notes were examined for details of illness, influenza vaccination, admissions to hospital, and recognised complications defined by criteria which could be identified in practice records (table I). Details of previous chronic illnesses and of numbers of consultations in the previous year were documented.

Statistics-Complication rates were calculated with $95 \%$ confidence intervals by using standard error of proportion or, where observed proportions were less than $0 \cdot 1$, the Poisson distribution. ${ }^{12}$ The rates in cases and controls were compared by matched univariate and multivariate analysis performed in Epi Info version $5^{13}$ by using the Mantel-Haenszel version of the $\chi^{2}$ test. Vaccine efficacy was determined overall and for the subgroups of cases and controls with conditions for which vaccination was indicated in the chief medical officer's annual guidelines ${ }^{14}$ by using the MantelHaenszel test (unmatched). Complication rates in cases with and without conditions for which vaccination was indicated were compared by using the Mantel-

TABLE I-Definitions of complications of influenza

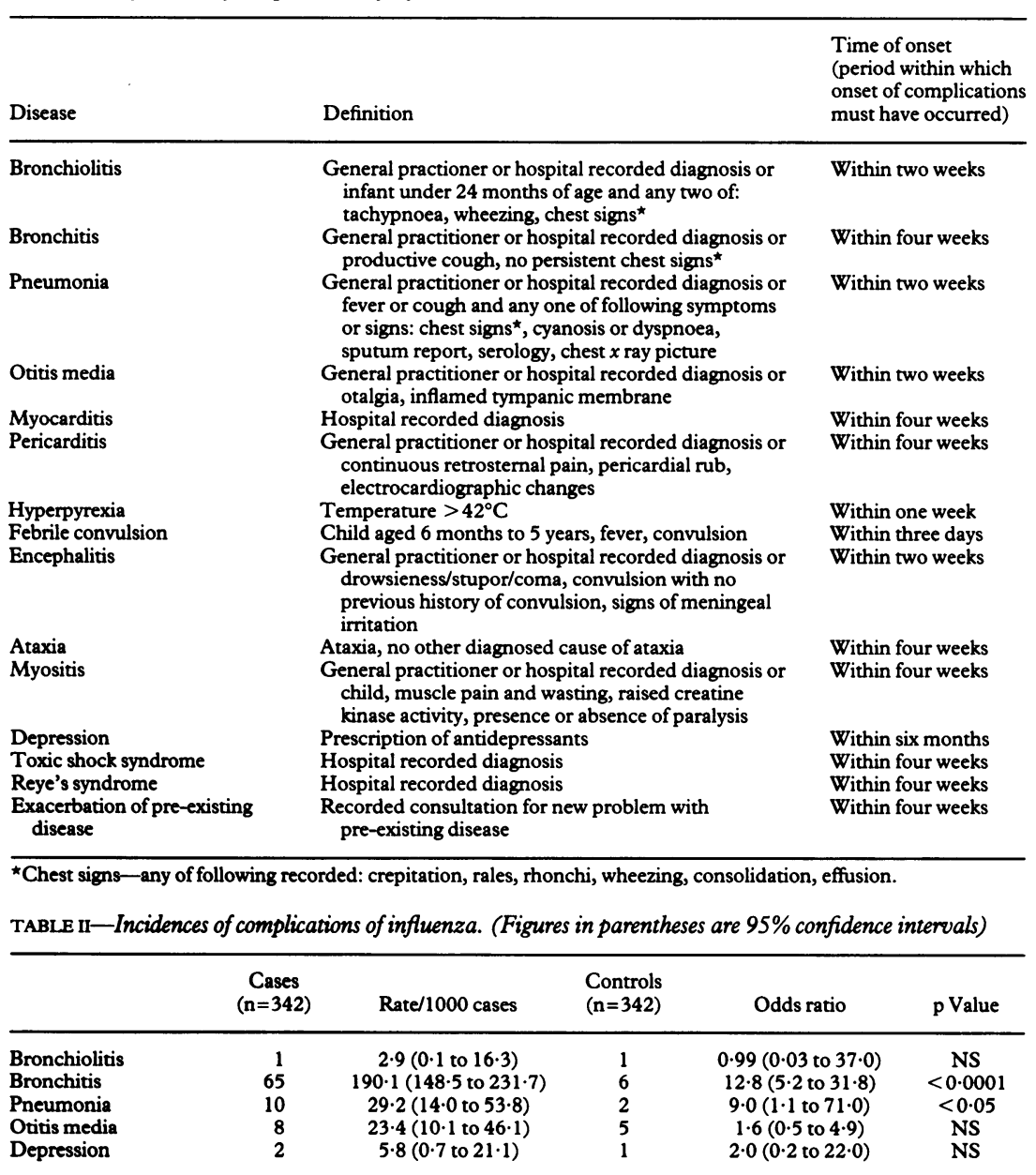

Haenszel test and by logistic regression, MULTLR, ${ }^{15}$ to allow for the effect of age as a continuous variable.

\section{Results}

Three hundred and ninety five cases were on the register, all occurring over the epidemic period (figure). Records of 43 cases could not be located. Of these, three had died after the study period (one of ischaemic heart disease and one of a cerebrovascular event, both over a year after the epidemic, and one in a road accident eight months after) and 31 had moved away. Ten controls' records could not be located. Analysis was performed on 342 case-control pairs.

There were no (upper 95\% confidence limit 3.7) cases of myocarditis, pericarditis, hyperpyrexia, febrile convulsion, encephalitis, ataxia, myositis, toxic shock syndrome, Reye's syndrome, or death. An upper $95 \%$ confidence limit of 3.7 was equivalent to an incidence of these complications of $10 \cdot 8 / 1000$ cases and a population incidence of $16 \cdot 8 / 100000$. Only two cases were admitted to hospital - equivalent to a rate of $9 \cdot 1 / 100000$ population (upper $95 \%$ confidence limit $32 \cdot 7 / 100000)$. The incidence of complications is given in table II. Bronchitis (odds ratio 12.8; $<<0.0001$ ) and pneumonia (odds ratio $9 \cdot 0 ; p<0.05$ ) were significantly commoner in cases. The mean number of consultations in the preceding year among cases was $6 \cdot 1$ and among controls was $4.2(p<0.0001)$. When this was allowed for only bronchitis occurred significantly more frequently in cases (summary odds ratio 9.7; $<<0.0001$ ).

When cases were considered on their own, out of the total of 342 , there were 38 for whom vaccine was recommended. Fifteen developed bronchitis compared with 50 of the remaining 304 cases for whom vaccine was not recommended (odds ratio 3.3; $\mathrm{p}<0.0001)$. When age was allowed for the odds ratio became $2.4(p<0.05)$. Considering the conditions for which vaccination is recommended individually, there were five cases with pre-existing diabetes mellitus. Bronchitis, as a complication of influenza, occurred in all five compared with 60 of 337 cases without diabetes mellitus (odds ratio undefined; $p<0.001$ ). There were 26 cases with pre-existing ischaemic heart disease. Ten developed bronchitis as a complication of influenza compared with 55 of 316 cases without ischaemic heart disease (odds ratio $2.9 ; \mathrm{p}<0.01$ ). Of nine cases with pre-existing chronic obstructive airways disease, two developed bronchitis as a complication of influenza compared with 63 of 333 without chronic obstructive airways disease (odds ratio $1 \cdot 2 ; \mathrm{p}=\mathrm{NS}$ ). Being elderly ( $>65$ years) was a risk factor for bronchitis $(16 / 41 v 49$ / 301 ; odds ratio $3 \cdot 3 ; p<0.001$ ) even after allowing for intercurrent conditions for which vaccination is recommended (summary odds ratio $2.38 ; p<0.001$ ).

Eight cases and seven controls had been vaccinated -an overall rate in the subjects studied of $2 \cdot 2 \%$. Among those at risk, according to chief medical officer guidelines, $4.5 \%$ were vaccinated and observed vaccine efficacy was $63 \%$ ( $1 / 38$ cases $v 2 / 28$ controls; NS). Altogether $6 \cdot 1 \%$ of those aged over 65 were vaccinated with an efficacy of $77 \%$ (1/41 cases $v$ 4/41 controls; NS). For those both over 65 and at risk, efficacy was $100 \%(0 / 16$ cases $v 2 / 16$ controls; NS).

\section{Discussion}

This was a community based study of influenza as it presents to general practitioners. It could not tell us about patients who stayed at home and did not consult. Nevertheless, although validation of case reporting during an influenza A outbreak in Wales in 1988-9 showed such underreporting to be of the order of tenfold, ${ }^{16}$ probably those experiencing more severe symptoms and complications would have contacted 
their doctor. The study should therefore have ascertained more serious cases and provided an accurate picture of the more serious community morbidity associated with the $1989-90$ epidemic. With regard to the accuracy of the diagnoses and the completeness of reporting, although no systematic laboratory confirmation of the diagnoses was made, general practitioners are well able to discriminate between any flu-like illness and true influenza during an epidemic. ${ }^{17} \mathrm{H} 3 \mathrm{~N} 2$ influenza $A$ was shown to be circulating in the communities at the time.

Many recognised complications, including death, were not seen. In Wales (population 2.87 million) there was an estimated excess of registered deaths of 1627 during the epidemic, of which only one in 10 were assigned to influenza. ${ }^{18}$ This would equate with an incidence of death ascribed to influenza of $5 \cdot 66 / 100000$ total population and is within the $95 \%$ confidence interval of the zero incidence observed in the study.

The rate of hospital admission would equate with a demand for some $20-30$ beds in a "typical" 250000 population health district in Britain over the epidemic period. It was much less than the rate of $160 / 100000$ observed in the United States, ${ }^{19}$ which may reflect the greater availability and use of hospital inpatient care there. There was no suggestion from clinicians that the British epidemic was unusually mild.

Bronchitis was the only complication of influenza occurring more commonly in cases than controls. The incidence of bronchitis and pneumonia together was $219 \cdot 3 / 1000$ (95\% confidence interval $175 \cdot 4$ to $263 \cdot 2$ ) compared with a previous study in Britain which found rates of lower respiratory tract infections (laryngitis, tracheitis, bronchitis, pneumonia) in laboratory confirmed cases of $253 \cdot 6 / 1000$. $^{3}$

Pre-existing chronic illness, particularly those conditions for which vaccination is recommended in the United Kingdom, was associated with significantly raised levels of bronchitis as a complication of influenza. In effect that vindicated the relevant part of the guidance. Of the conditions individually present in the sample, ischaemic heart disease, diabetes mellitus, and chronic obstructive airways disease all showed a heightened risk of bronchitis, although the numbers for chronic obstructive airways disease were too small to achieve statistical significance. Being elderly (over 65 ), which is not generally regarded as an indication for vaccination in the United Kingdom, was also associated with a significantly increased risk of bronchitis.

The vaccine efficacy observed was consistent with the $60-80 \%$ reported when vaccine and epidemic strain were closely matched. ${ }^{20}$ Nevertheless, uptake was too low at $4.5 \%$ for those with an indication for vaccination to exhibit this efficacy with confidence. Why is vaccine apparently not getting to those who would benefit from it? Professional workers may harbour doubts about efficacy and indications. They may also find it difficult in a general practice setting to identify patients for whom it is indicated as, unlike with childhood vaccinations, no single convenient register may exist. Similarly patients may well be unaware of the need for annual vaccination, not perceive the risk as serious, and ultimately not come forward.

In the 1989 influenza $A$ epidemic a significant excess of cases in two general practices were complicated by lower respiratory tract infection. Vaccine did not apparently reach those identified as appropriate recipients in official policy. Does this matter? Is vaccination worth while, given the relative infrequency of many of the commonly listed complications. We found 15 cases of acute bronchitis complicating influenza in 38 patients with conditions for which vaccination is recommended by the chief medical officer from a total list of 22076 . If our experience is typical of the United Kingdom as a whole over 30000 cases of acute bronchitis must have occurred over the seven weeks of the epidemic, a large proportion of which were potentially preventable by vaccination. This would have been without extending the criteria on which vaccination is currently recommended to, for example, all elderly people. On the limited evidence from this study this should also be further considered. While vaccination coverage is so extremely low unequivocal evidence of benefit cannot be proved. This also means that most of any such benefit is not being obtained.

We thank $\mathrm{Mr}$ Colin Morgan, practice manager, and the staff at Swansea, and Mrs Sybil Neale, practice manager, and the staff at Pontypridd. This work was supported in part by a grant from the Welsh Office chief medical officer's research budget for 1989-90.

1 Schaffner W. Influenza from the public health perspective. Am $f$ Med 1987;82(suppl 6A):61-3.

2 Grist N. Influenza update. Practitioner 1989;233:56-9.

3 Miller DL, Lee JA. Influenza in Britain. Journal of Hygiene (Cambridge) 1969;67:559-72.

4 Hall CR, Douglas RG. Infections of the upper respiratory tract. In: Reese RE, Douglas RG, eds. A practical approach to infectious disease. Boston: Little, Brown, 1986 .

5 Nagington J, Rubeinstein D. Influenza. In: Weatherall DJ, Ledingham JGG, Warrell DA, eds. Oxford textbook of medicine. Vol 1. Oxford: Oxford University Press, 1983.

6 Dan BB. Toxic shock syndrome: back to the future. JAMA 1987;257:1094-5.

7 Stuart-Harris $\mathrm{CH}$. Influenza and its complications-I. $B M$ I 1966;i:149-50.

8 Stuart-Harris CH. Influenza and its complications-II. BMF 1966;i:217-8.

9 Cate TR. Clinical manifestations and consequences of influenza. IAMA 1987;82:15-8.

10 Fleming DM, Crombie DL, Norbury CA, Cross KW. Observations on the influenza epidemic of November/December 1989. Br $\mathcal{F}$ Gen Pract 1990;40: 495-7.

11 Palmer SR, Smith RMM. GP surveillance of infections in Wales. Communicable Disease Report 1991;1:R25-8. (Review No 3.)

12 Gardner MJ, Altman DG. Statistics with confidence. London: British Medica Journal, 1989.

13 Dean $\mathrm{AD}$, Dean JA, Burton AH, Dicker RC. Epi Info, version 5: a wond processing, database and statistics program for epidemiology on micro-computer. Stone Mountain, Georgia: USD, 1990.

14 Chief Medical Officer. Influenza. Cardiff: Welsh Office, 1990. (CMO(90)9.)

15 Nelson Campos-Hilho BS, Franco EL. MULTLR: a microcomputer program for multiple logistic regression by unconditional and conditional maximum likelihood multiple logistic regression by unconditional and conditional maximum likelihod
methods. Sao Paulo, Brazil: Ludwig Institute for Cancer Research, 1988.

16 Palmer SR, Salmon RL, Smith RMM. Influenza surveillance-Wales, 1988-89. MMWR 1990;39:913-4.

17 Fleming DM, Ayres JG. Diagnosis and patterns of incidence of influenza, influenza-like illness and the common cold in general practice. $\exists R$ Coll $G e n$ Pract 1988;38: 159-62.

18 Ashley J, Smith T, Dunnell K. Deaths in Great Britain associated with the influenza epidemic of 1989/90. Population Trends 1991;65:16-20.

19 Shann F. Modern vaccines. Pneumococcus and influenza. Lancet 1990;33 898-901.

20 Nicholson KG. Influenza vaccination and the elderly. BMF 1990;301:617-8.

(Accepted 8 April 1993) 